\title{
A TRANSDISCIPLINARIDADE E A EDUCAÇÃO DE JOVENS E ADULTOS
}

\author{
Transdisciplinarity and the young and adults' education
}

Lênio Fernandes Levy ${ }^{1}$

\section{RESUMO}

Tomando-se por base a seguinte máxima transdisciplinar: "do todo em direção às partes e das partes rumo ao todo", propõem-se neste artigo (em especial no que se refere ao segundo trecho da citação em foco) ações educacionais dirigidas pelas chamadas Duplas Heterogêneas de Professores (DHP), que integram docentes com formação (cada um deles) em disciplinas (partes) diferentes, os quais, trabalhando em conjunto (inclusive com os alunos), no mesmo espaço-tempo pedagógico, buscam/buscariam construir ligações entre os conteúdos pertencentes aos (dois) campos de conhecimento em questão, efetivando-se um caminhar das partes e de suas mútuas (e múltiplas) conexões em direção ao todo. $\mathrm{O}$ público escolhido é/foi o da Educação de Jovens e Adultos EJA (no ambiente da escola pública municipal), pois se acredita que as informações extra-escolares acumuladas pelo estudante jovem/adulto, apesar de sua educação formal deficitária, possam contribuir para que ele estabeleça, se corretamente orientado, relações/ligações intelectuais diversas. Apesar (ou além) das pesquisas exploratórias, em campo, que culminaram com resultados constantes em 5 (cinco) tabelas, predominam, quanto à metodologia adotada neste trabalho, $\mathrm{o}$ caminhar teórico.

Palavras-chave : Complexidade; transdisciplinaridade; Dupla Heterogênea de Professores; escola pública; EJA; ensino de Matemática.

\section{ABSTRACT}

Taking as a basis the following maximum trans: "the whole toward parts and from the parts into the whole" it is proposed in this paper (with particular reference to the second sentence of the quote in focus) educational activities directed by what we call Heterogeneous Pairs of Teachers (HPT), which represents teachers with training (each) in different subjects (parts), which, working together (including with the students) in the same space-time teaching, would build links between the content belonging to the (two) fields of knowledge at issue, effecting a path to the parts and their mutual (and multiples) connections into the whole. The chosen audience is Adult and Youth Education AYE (at public school's environment), because there's a belief that the extra-curricular informations accumulated by the young and adult student, despite his formal education deficit, may help him lay down, if properly oriented, several intellectuals relationships / connections. Despite (or beyond) the exploratory field researches, culminating with consistent results within five (5) predominant tables, as the methodology adopted in this rsearch, the theoretical path..

Keywords: Complexity; Transdisciplinarity; Heterogeneous Dual Teacher; Public school; young and adult's Education; Mathematics Teaching.

O pensamento complexo não substitui a separabilidade pela inseparabilidade ele convoca uma dialógica que utiliza o separável mas o insere na inseparabilidade

Morin (2000, p.200).

${ }^{1}$ Professor do Instituto Federal de Educação Ciência e Tecnologia (IFPA). Mestre em Educação em Ciências e Matemáticas pela UFPA. 
O decurso etário/temporal é crucial para a progressão da sedimentação de conhecimentos pessoais. O homem é, essencialmente, um ser pensante, e, como tal, desenvolve-se ao (re)processar as informações advindas dos eventos que permeiam, momento a momento, sua existência. A mente de um adulto encontrase impregnada de idéias que (nela) não existiam (com tal complexidade estrutural) outrora, que não habitavam seu espírito quando este ainda saboreava os frutos da infância e/ou da adolescência. "A idade cronológica tende a propiciar oportunidades de vivências e relações pelas quais crianças e adolescentes, em geral, ainda não passaram" (FONSECA ${ }^{2}, 2002$, p.22). Ao arcabouço cultural construído pelo indivíduo ao longo de sua existência, somam-se outros aspectos que determinam seu grau de competência cognitiva, havendo uma tendência cada vez mais robusta (entre psicólogos evolutivos) de não aceitação da hipótese de declínio das faculdades mentais em função do amadurecimento/envelhecimento corpóreo. A seguinte declaração de Fonseca é deveras pertinente:

Essa perspectiva de imputar à idade do aprendiz uma responsabilidade orgânica por eventuais dificuldades no aprendizado, apesar de freqüente no senso comum, não encontra respaldo em estudos (que, como vimos, são raros) sobre o funcionamento intelectual do adulto. Ao afirmar que "as pessoas humanas têm um bom nível de competência cognitiva até uma idade avançada (desde logo, acima dos 75 anos)", Palácios (1995, p. 312 ) a ponta para um redimensionamento das considerações sobre a natureza das condições que determinam as possibilidades de aprendizagem e construção de conhecimento na idade adulta, apoiando-se na posição de psicólogos evolutivos, cada vez mais convencidos de que o que determina o nível de competência cognitiva das pessoas mais velhas não é tanto a idade em si mesma quanto uma série de fatores de natureza diversa. Entre esses fatores, Palácios destaca o nível de saúde, o nível educativo e cultural, a experiência profissional e o tônus vital da pessoa (sua motivação, seu bemestar psicológico...) (2002, p.21-22).

Não obstante a fragilidade escolar/acadêmica que caracteriza a maioria dos estudantes da EJA é válido crer, haja vista os motivos citados, que atributos cognitivos outros, adquiridos (por eles) previamente, possam permitir-lhes lograr êxito em eventuais tentativas de construções transdisciplinares, porquanto o conhecimento produzido fora da escola também é componente da teia (complexa) cultural. Segundo Petraglia ${ }^{3}$ :

(...) Assim, tanto educadores como escola, enquanto estrutura organizacional educativa, não podem perder de vista que a construção da identidade da escola passa, primeiramente, pela construção individual da identidade de seus membros, que são sujeitos desse processo, como também do processo do conhecimento, que nessa escola se desenvolve.

E é sob esse prisma que se coloca o trabalho de Edgar Morin no sentido de provocar a reflexão da educação, pautada na consciência da complexidade presente em toda a realidade, ou seja, é fundamental que o educador compreenda a teia de relações existente entre todas as coisas, para que possa pensar a ciência uma e múltipla, simultaneamente.

O subsídio de seu pensamento para a educação está na teoria e na prática do "tudo se liga a tudo", e é no "aprender a aprender" que o educador transforma a sua ação numa prática pedagógica transformadora (2001, p.73).

A autora prossegue, asseverando que:

A transdisciplinaridade é fruto do paradigma da complexidade, fundamentada por uma epistemologia da complexidade, também estando presente em seu seio as interligações de Sujeito-Objeto-Ambiente.

(...) Nesse contexto, sempre devem ser refletidas e ampliadas as discussões acerca da importância das relações entre os conteúdos de uma disciplina e outra disciplina; entre as disciplinas e o curso; entre as disciplinas e a vida, e

\footnotetext{
${ }^{2}$ Maria da Conceição Ferreira Reis Fonseca é mestre em Educação Matemática pela UNESP de Rio Claro e doutora em Educação pela UNICAMP. É professora na Faculdade de Educação da UFMG.

${ }^{3}$ Izabel Cristina Petraglia é pedagoga, psicóloga e doutora em Educação: Administração Escolar pela Universidade de São Paulo. É pesquisadora da complexidade e da transdisciplinaridade.
} 
assim sucessivamente, a fim de não se estimular a elaboração de conhecimentos parcelados advindos do pensamento linear, mas promovendo-se a construção de um saber uno, com visão conjunta e de um todo composto por muitos aspectos (Ibidem, p.75).

Esse manancial de conhecimentos previamente adquiridos/construídos necessita, contudo, de instrumental metodológico apropriado (sugerimos ações transdisciplinares dirigidas por $\mathrm{DHP}^{4}$ ) para que seus detentores, os estudantes da EJA, consigam fabricar (os) fios da teia complexa (que, em tese, "liga tudo a tudo"), visto que tal confecção nem sempre é trivial (as eventuais dificuldades são parcialmente devidas à mentalidade compartimentalizada que se instaurou na cultura, sobretudo a ocidental, ao longo dos últimos séculos), a exemplo dos fatos a seguir relatados, os quais foram constatados por ocasião de investigação a que procedemos em ambiente escolar da EJA.

A indagação que norteia o presente artigo ("Como os professores devem agir para fomentar a elevação da visão de união e de totalidade de conhecimentos dos atuais alunos de Matemática da educação pública municipal de jovens e adultos de Belém, Pará?") foi motivada (em parte) pela pesquisa exploratória que realizamos em novembro/2002 com uma amostra de 61 (sessenta e um) estudantes da EJA de duas escolas públicas municipais de Belém, matriculados no $4^{\circ}$ turno (à noite), quando lhes foi inquirido se concebiam algum tipo de relação e qual(quais) seria(m) essa(s) relação(ões) entre Matemática e: Artes, História, Geografia, Ciências, Português, Mundo Extra-Classe, Profissões/Trabalho, Política e Religião. Para tanto, receberam questionários impressos (vide ANEXO A MODELO DE QUESTIONÁRIO), e se lhes disponibilizou o tempo de 40 (quarenta) minutos a fim de que concluíssem as respectivas apreciações/considerações, tendo-lhes sido informada previamente a necessidade de que realizassem a tarefa na própria sala de aula (evitando-se com isso a possibilidade de recurso a fontes outras, que não seus próprios conhecimentos, o que desvirtuaria a pesquisa).
Buscávamos, pois, a obtenção de uma "radiografia" de sua criatividade no tocante ao estabelecimento de relações entre conhecimentos afetos a disciplinas ou a campos muitas vezes tidos como incomunicáveis entre si.

Cada uma das 4 (quatro) tabelas iniciais diz respeito a uma turma específica, de um total de 4 (quatro) pesquisadas (na Escola Ida Oliveira, as turmas $n^{\circ} 443$ e $n^{0} 342$, e, na Escola Édson Luís, as turmas $n^{\circ} 441$ e $\left.n^{\circ} 341\right)$. A $5^{\text {a }}$ (quinta) tabela dá-nos um panorama envolvendo os dois colégios. As linhas (dispostas horizontalmente) das tabelas indicam os nomes das disciplinas (ou dos campos) em questão e as quantidades (tanto em números absolutos quanto em percentuais) das respostas que julgamos aceitáveis (SIM), bem como daquelas que consideramos desconexas (NÃO), juntamente com as deixadas em branco (NÃO). $\mathrm{O}$ resultado final, ou seja, o constante na tabela $\left(n^{\circ} 5\right)$ correspondente à reunião de ambas as escolas, indica/indicou uma média de $70,30 \%$ de respostas em branco ou sem qualquer consistência plausível. No tocante ao percentual restante $(29,69 \%)$, a grande maioria dos vínculos que confirmamos restringese/restringiu-se às operações aritméticas de adição e de subtração (e sabemos que a Matemática, mesmo a escolar, vai muito além desse patamar), diagnóstico da pouca habitualidade estudantil (apesar de seus conhecimentos extra-escolares prévios) no que concerne à produção de ligações entre os conteúdos/assuntos diversos, muito menos no que tange à transcendência inerente ao vislumbre da/de uma totalidade, atributos (visões de união e de totalidade) cuja consecução corresponde, grosso modo, ao objetivo da transdisciplinaridade.

Nas páginas seguintes, apresentamos os resultados (as tabelas) da sondagem que ajudou a motivar a questão que ora nos serve de norte ("Como os professores devem agir para fomentar a elevação da visão de união e de totalidade de conhecimentos dos atuais alunos de Matemática da educação pública municipal de jovens e adultos de Belém, Pará?"), os quais

\footnotetext{
${ }^{4}$ Propomos que as aulas sejam ministradas não por um único professor, mas pelo sistema que concebemos e que resolvemos chamar de Duplas Heterogêneas de Professores (DHP). Eles, os professores dessas díades, trabalhariam em parceria (entre si e com os estudantes), no mesmo espaço-tempo pedagógico, permutando idéias, criando vínculos intra (referentes a tópicos internos das disciplinas) e interdisciplinares, buscando, em instância maior, uma proximidade cada vez mais estreita da visão de totalidade (o que equivale à transdisciplinaridade, isto é, ao processo entre as, através das e além das disciplinas)
} 
(os resultados) se constituem no flagrante de uma realidade discente impregnada de fragmentação, fruto de um "fazer" docente também retalhado/fragmentado. Cabe salientar que, mesmo antes de tais perquirições, nós sentíamos - em função dos contatos diários travados com os estudantes - a existência do problema, tanto que já cogitávamos sobre as DHP (nossa propositura) como eventual solução.

TABELA 1 Distribuição das respostas de 20 (vinte) alunos da turma 443 (Escola Ida Oliveira novembro/2002)

*Conseguiram estabelecer alguma relação entre Matemática e:

\begin{tabular}{|c|c|c|c|c|}
\hline DISCIPLINAS & & & & \\
\hline & $\mathrm{N}^{\circ}$ & $\%$ & $\mathrm{~N}^{\mathrm{o}}$ & $\%$ \\
\hline 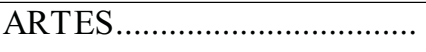 & 01 & 05,00 & 19 & 95,00 \\
\hline 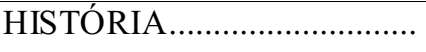 & 05 & 25,00 & 15 & 75,00 \\
\hline 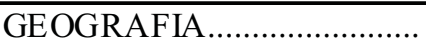 & 04 & 20,00 & 16 & 80,00 \\
\hline 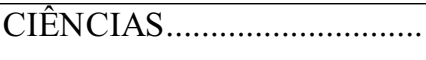 & 11 & 55,00 & 09 & 45,00 \\
\hline PORTUGUÊS.............................. & 01 & 05,00 & 19 & 95,00 \\
\hline O MUNDO EXTRA-CLAS SE.. & 11 & 55,00 & 09 & 45,00 \\
\hline TRABALHO............................... & 07 & 35,00 & 13 & 65,00 \\
\hline 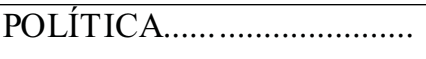 & 08 & 40,00 & 12 & 60,00 \\
\hline 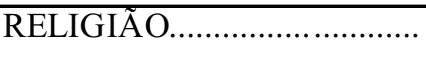 & 01 & 05,00 & 19 & 95,00 \\
\hline TOTAL & 49 & 27,22 & 131 & 72,77 \\
\hline
\end{tabular}

TABELA 2 Distribuição das respostas de 18 (dezoito) alunos da turma 342 (Escola Ida Oliveira novembro/2002)

*Conseguiram estabelecer alguma relação entre a Matemática e:

\begin{tabular}{|c|c|c|c|c|}
\hline DISCIPLINAS & & & & \\
\hline & $\mathrm{N}^{\circ}$ & $\%$ & $\mathrm{~N}^{\mathrm{o}}$ & $\%$ \\
\hline ARTES...................................... & 01 & 05,55 & 17 & 94,45 \\
\hline HISTÓRIA.................................. & 02 & 11,11 & 16 & 88,89 \\
\hline GEOGRAFIA............................... & 02 & 11,11 & 16 & 88,89 \\
\hline 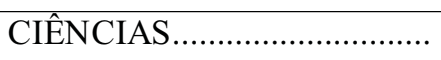 & 02 & 11,11 & 16 & 88,89 \\
\hline 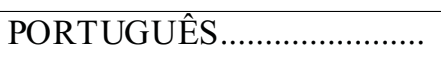 & 01 & 05,55 & 17 & 94,45 \\
\hline O MUNDO EXTRA-CLASSE.. & 04 & 22,22 & 14 & 77,78 \\
\hline 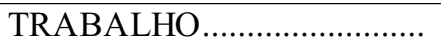 & 08 & 44,44 & 10 & 55,56 \\
\hline 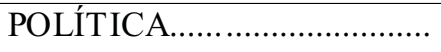 & 03 & 16,66 & 15 & 83,34 \\
\hline RELIGIÃO................................. & 01 & 05,55 & 17 & 94,45 \\
\hline TOTAL & 24 & 14,81 & 138 & 85,18 \\
\hline
\end{tabular}


TABELA 3 Distribuição das respostas de 11 (onze) alunos da turma 441 (Escola Édson Luís novembro/2002)

*Conseguiram estabelecer alguma relação entre Matemática e:

\begin{tabular}{|c|c|c|c|c|}
\hline \multirow[t]{2}{*}{ DISCIPLINAS } & \multicolumn{2}{|c|}{ SIM } & \multicolumn{2}{|c|}{ NÃO } \\
\hline & $\mathrm{N}^{\mathrm{o}}$ & $\%$ & $\mathrm{~N}^{\mathrm{o}}$ & $\%$ \\
\hline ARTES................................. & 03 & 27,27 & 08 & 72,73 \\
\hline HISTÓRIA............................ & 06 & 54,54 & 05 & 45,46 \\
\hline GEOGRAFIA ....................... & 05 & 45,45 & 06 & 54,55 \\
\hline CIÊNCIAS........................... & 06 & 54,54 & 05 & 45,46 \\
\hline PORTUGUÊS....................... & 02 & 18,18 & 09 & 81,82 \\
\hline O MUNDO EXTRA-CLAS SE.. & 11 & 100,0 & 00 & 00,00 \\
\hline TRABALHO .......................... & 07 & 63,63 & 04 & 36,37 \\
\hline POLÍTICA................................ & 08 & 72,72 & 03 & 27,28 \\
\hline 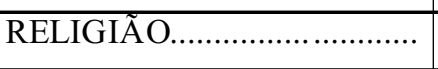 & 02 & 18,18 & 09 & 81,82 \\
\hline TOTAL & 50 & 50,50 & 49 & 49,50 \\
\hline
\end{tabular}

TABELA 4 Distribuição das respostas de 12 (doze) alunos da turma 341 (Escola Édson Luís novembro/2002)

*Conseguiram estabelecer alguma relação entre Matemática e:

\begin{tabular}{|c|c|c|c|c|}
\hline DISCIPLINAS & & & & \\
\hline & $\mathrm{N}^{\mathrm{o}}$ & $\%$ & $\mathrm{~N}^{\mathrm{o}}$ & $\%$ \\
\hline ARTES................................... & 04 & 33,33 & 08 & 66,67 \\
\hline HISTÓRIA............................. & 07 & 58,33 & 05 & 41,67 \\
\hline GEOGRAFIA.......................... & 02 & 16,16 & 10 & 83,34 \\
\hline CIÊNCIAS ............................ & 01 & 08,33 & 11 & 91,67 \\
\hline PORTUGUÊS....................... & 04 & 33,33 & 08 & 66,67 \\
\hline O MUNDO EXTRA-CLASSE.. & 09 & 75,00 & 03 & 25,00 \\
\hline TRABALHO ........... & 07 & 58,33 & 05 & 41,67 \\
\hline POLÍTICA............................. & 06 & 50,00 & 06 & 50,00 \\
\hline RELIGIÃO.......................... & 00 & 00,00 & 12 & 100,0 \\
\hline TOTAL & 40 & 37,03 & 68 & 62,97 \\
\hline
\end{tabular}


TABELA5 Distribuição das respostas de 61 (sessenta e um) alunos das turmas 443, 342 (Escola Ida Oliveira), 441 e 341 (Escola Édson Luís) novembro/2002

*Conseguiram estabelecer alguma relação entre Matemática e:

\begin{tabular}{|c|c|c|c|c|}
\hline \multirow[t]{2}{*}{ DISCIPLINAS } & \multicolumn{2}{|c|}{ SIM } & \multicolumn{2}{|c|}{ NÃO } \\
\hline & $\mathrm{N}^{\mathrm{o}}$ & $\%$ & $\mathrm{~N}^{\mathrm{o}}$ & $\%$ \\
\hline ARTES.................................. & 009 & 14,75 & 052 & 85,25 \\
\hline HISTÓRIA............................... & 020 & 32,78 & 041 & 67,22 \\
\hline GEOGRAFIA.......................... & 013 & 21,31 & 048 & 78,69 \\
\hline CIÊNCIAS............................. & 020 & 32,78 & 041 & 67,22 \\
\hline PORTUGUÊS........................ & 008 & 13,11 & 053 & 86,89 \\
\hline O MUNDO EXTRA-CLASSE.. & 035 & 57,37 & 026 & 42,63 \\
\hline TRABALHO........................... & 029 & 47,54 & 032 & 52,46 \\
\hline POLÍTICA............................... & 025 & 40,98 & 036 & 59,02 \\
\hline RELIGIÃO............................. & 004 & 06,55 & 057 & 93,45 \\
\hline TOTAL & 163 & 29,69 & 386 & 70,30 \\
\hline
\end{tabular}

As diferenças/variações percentuais constatadas entre as turmas (em cada classe/turma, também ocorreram discrepâncias entre resultados afetos a disciplinas/áreas diversas) apenas comprovam/comprovaram a impossibilidade de se equacionar/determinar, nos moldes do paradigma moderno, o comportamento humano, porquanto a "incerteza" é, hoje sabemos, marca indelével da complexidade do homem / da natureza. Entretanto, é razoável concluir que, no domínio pedagógico, existe muito que podemos (e devemos) realizar.

Apesar de os números serem, de um modo geral, pouco otimistas, reiteramos nossa concepção de que uma prática pedagógica orquestrada por DHP, em conjunção com o cabedal de conhecimentos prévios/acumulados de que é dotada a clientela da EJA, poderia alterálos (os números) para níveis mais aceitáveis. Frisamos, por oportuno, que as abordagens transdisciplinares não fazem parte (de maneira sistematizada) da rotina docente das duas escolas investigadas, embora sejam (algumas abordagens de tal gênero) sugeridas em reuniões de começo de ano. Acreditamos que a não concretização desse intento deva-se à pouca praticidade das idéias até hoje defendidas (entre as quais ainda não constaram aquelas acerca de ações transdisciplinares dirigidas por DHP).

\section{REFERÊNCIAS}

FONSECA, M. C. F. R. Educação matemática de jovens e adultos: especificidades, desafios e contribuições. Belo Horizonte: Autêntica, 2002.

MORIN, E. O pensamento complexo, um pensamento que pensa. In: MORIN, E.; LE MOIGNE, J. L. A inteligência da complexidade. São Paulo: Peirópolis, 2000.

PETRAGLIA, I. C. Edgar Morin: A educação e a complexidade do ser e do saber. 6.ed. Rio de Janeiro: Vozes, 2001. 